\title{
With or without the B-A-C-H Motive? Bartók's Hesitation in Writing his First String Quartet
}

\author{
László SOMFAI \\ Bartók Archives, Institute for Musicology \\ Research Centre for the Humanities \\ Táncsics Mihály u. 7., H-1014 Budapest, Hungary \\ Email: somfai.laszlo@btk.mta.hu
}

Received: August 2019; accepted: September 2019

\begin{abstract}
Considering the appearance of the musical cryptogram "B-A-C-H" (B-flatA-C-B-natural) in well-known works up to the time of his First String Quartet (1908/1909), Béla Bartók knew Liszt's Fantasy and Fugue on the Theme B-A-C-H, presumably also Schumann's Sechs Fugen über den Namen Bach, and Reger's Fantasia and Fugue on B-A-C-H for organ. Such compositions quoted the celebrated motive, typically as a starting point, with the relevant (aforementioned) pitches because the musical cryptogram in this way allowed immediate recognition of the reference to the name of the Leipzig composer. However, Bartók's planned "B-A-C-H" quotation in the development section of the sonata-form second movement of his First Quartet was not a typical homage to Johann Sebastian Bach but rather a vision: a distorted reference to the symbolic "B-A-C-H" motive. Undoubtedly Bartók liked this episode. There is reason to believe that his friend Zoltán Kodály advised him to leave out the inorganic and distorted "B-A-C-H" allusion.
\end{abstract}

Keywords: Béla Bartók, "B-A-C-H" motive, First String Quartet, composition history, Zoltán Kodály

To understand the case of the initially elaborated, and subsequently discarded, "B-A-C-H" reference in the second movement of Béla Bartók's First String Quartet (1908-1909, sketches already from 1907), two facts should be emphasized in the first instance. Béla Bartók (1881-1945), as with several pianist-composers, had a secure absolute pitch since childhood. Moreover, he committed preliminary compositional ideas to paper, in the form of sketches, as he conceived them. In the final version of a score (with very few exceptions), he retained the initial 
key. ${ }^{1}$ It appears that for Bartók, the precise pitch and octave formed part of the immovable constituents of basic musical ideas of a new composition.

Although the extensive use of this famous motive became fashionable in the twentieth century after the composition of Bartók's First String Quartet, ${ }^{2}$ the appearance of the musical cryptogram "B-A-C-H" (B-flat-A-C-B-natural) was well known from works prior to his quartet. He certainly knew Liszt's Fantasy and Fugue on the Theme B-A-C-H, presumably also Schumann's Sechs Fugen über den Namen Bach, and Reger's Fantasia and Fugue on B-A-C-H for organ. Such compositions quote the celebrated motive, typically as a starting point, using the relevant (aforementioned) pitches. In this manner the musical cryptogram in German (and in several other European languages, including Hungarian) ensured that the Leipzig composer's name would be immediately recognized.

However, Bartók's planned "B-A-C-H" quotation was not a typical homage to Johann Sebastian Bach, primarily because he did not quote the relevant pitches, but rather its transpositions. Furthermore, this musical reference does not serve as a starting point, it is an episode in his composition - a vision: a dream-like appearance of a familiar sound. Presented initially slow in the extreme and foregrounded before the action of the lower voices, this cryptogram is subsequently presented in a more energetic manner in a higher register - a distorted reference to the symbolic "B-A-C-H." This appears in the development section of the sonata-form second movement of his First String Quartet (after measure 195 in the printed version),

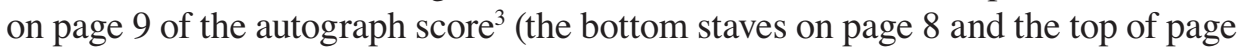
9, see Facsimiles 1-2).

In performance, this appearance of the famous motive would sound peculiar. Despite the motivic preparation in the lower voices in the previous measures (see second violin: $\mathrm{G}^{1}-\mathrm{F}$-sharp ${ }^{1}-\mathrm{A}-$ flat $^{1}-\mathrm{G}^{1}$, etc.), the entrance of the high notes in the first violin at rehearsal no. 19 is surreal: heard first in the $\boldsymbol{p p}$ sempre passage with two-measure $\boldsymbol{p}$ semplice of notes $\mathrm{B}^{2}-\mathrm{B}-$ flat $^{2}-\mathrm{C}$-sharp ${ }^{3}-\mathrm{C}$-natural ${ }^{3}$, followed by a rhythmically diminished and more energetic version of the same motive, a one-measure poco crescendo using the notes $\mathrm{E}^{3}$-D-sharp ${ }^{3}-\mathrm{F}$-sharp ${ }^{3}-\mathrm{E}$-sharp ${ }^{3}$. The supposed narrative of the short episode invites the researcher to question why Bartók quotes the well-known motive in transposed versions rather than the emblematic "B-A-C-H" (B-flat-A-C-B-natural) pitches. Perhaps because this is a vision, a depressing vision only?

1. A detailed study of sketches vs. final form is found in László SOMFAI, Béla Bartók: Composition, Concepts, and Autograph Sources (Berkeley, CA etc.: University of California Press, 1996), 33ff.

2. For an extensive list of compositions using the B-A-C-H motive, see Ulrich PRINZ, Joachim DORFMÜLLER and Konrad KÜSTER, "Die Tonfolge B-A-C-H in Kompositionen des 17. bis 20. Jahrhunderts: ein Verzeichnis," in 300 Jahre Johann Sebastian Bach: sein Werk in Handschriften und Dokumenten, Musikinstrumente seiner Zeit, seine Zeitgenossen: eine Ausstellung der Internationalen Bachakademie in der Staatsgalerie Stuttgart, 14.9. bis 27.10.1985, ed. by Ulrich PRINZ and Konrad KÜSTER (Tutzing: Hans Schneider, 1985), 389-419.

3. Peter Bartók's collection, 20FSS1 (photocopy in BBA). 
Facsimiles 1-2 The quotation of the B-A-C-H motive in the draft score on the bottom of p. 8 and the top of p. 9 (PB 20FSS1, photocopy in BBA)

Reproduced by kind permission of the Paul Sacher Stiftung, Basel
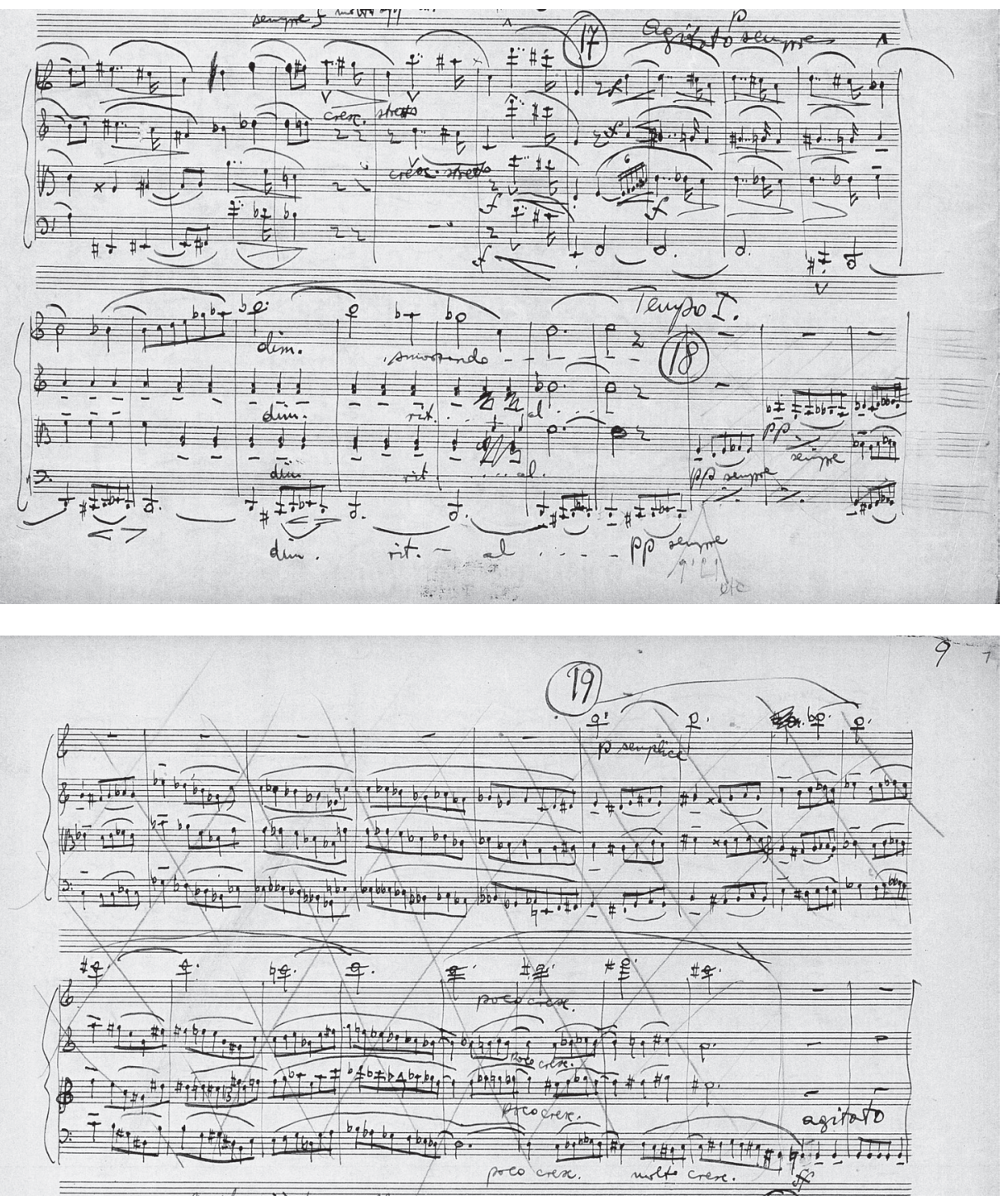
Undoubtedly Bartók liked this episode; when he gave the completed autograph score to a copyist, ${ }^{4}$ this section was not yet crossed out. The following discussion explores the possible reasons for later replacing this passage in the finalized score of his First String Quartet.

A speculative reason is related to his friend, Zoltán Kodály; there are grounds to suspect he advised Bartók to omit the inorganic and distorted "B-A-C-H" reference. As Kodály's penciled notes in the autograph of the First Quartet indicate, sometime in February or March of 1909 Bartók lent the score to his friend. It appears that Kodály received Bartók's draft manuscript up to page 8 (second movement, measure 195) only when these pages were already copied, ${ }^{5}$ whereas his notes on pages 10-13 (up to the third movement, measure 53) preceded the copying. Kodály's annotations, written in the margin in pencil - often only a question mark - are not numerous, but significant. ${ }^{6}$ In addition to suggesting corrections to enharmonic notation and part writing, mostly in the first movement, Kodály was hesitant with regards to this movement's abrupt ending. More importantly, following an initial reading, a private talk between the two friends surely ensued in which Kodály expressed his views concerning certain points of the form, which Bartók acknowledged, and presumably some of these critical remarks led to cuts. Significant improvements included cutting two measures after measure 42 in the first movement ${ }^{7}$ and five after measure 52 in the same movement (the latter is scrutinized below, see Facsimile 4).

Probably the most significant improvement resulting from Kodály's critique is the replacement of 27 measures of the development section in the second movement (measures 197ff, see Facsimiles 1-2) discussed here, in which Bartók quoted the transposed forms of the familiar B-A-C-H motive. The rewritten section is a genuine culmination point towards the end of the development section, arriving at a typical Bartókian hemiola phrase (the two measures before rehearsal number 19), which is a correction consistent with the practice of the mature Bartók (see Facsimile 3). ${ }^{8}$

From the two aforementioned edits in the first movement of the First String Quartet, the more substantial of the two, appearing before the beginning of the recapitulation of the contrapuntal Lento theme (see Facsimile 4 below), does not reveal a remark in Kodály's hand. Nevertheless it is reasonable to assume that he might have suggested an omission of this nature to Bartók. The improvement is immense: the two interrupted $\boldsymbol{p p}$ possibile measures followed by the $\boldsymbol{p} \boldsymbol{p}$ return of

4. Gábor Vásárhelyi, BH 37 (photocopy in BBA).

5. See ECRv in the forthcoming 30th volume of the Béla Bartók Complete Critical Commentary (BBCCE).

6. For the detailed list of Kodály's notes, see the forthcoming 30th volume of BBCCE.

7. See László SOMFAI, "Bartók 2. vonósnégyese és Kodály 'útbaigazítása”" [Bartók’s Second String Quartet and Kodály's “critical faculty”], Magyar Zene 46/2 (May 2008), 173.

8. A first publication and discussion of the rewritten section is found in SOMFAI, "Bartók 2. vonósnégyese és Kodály “útbaigazítása',” 167-182. 
FACSIMILE 3 The corrected version
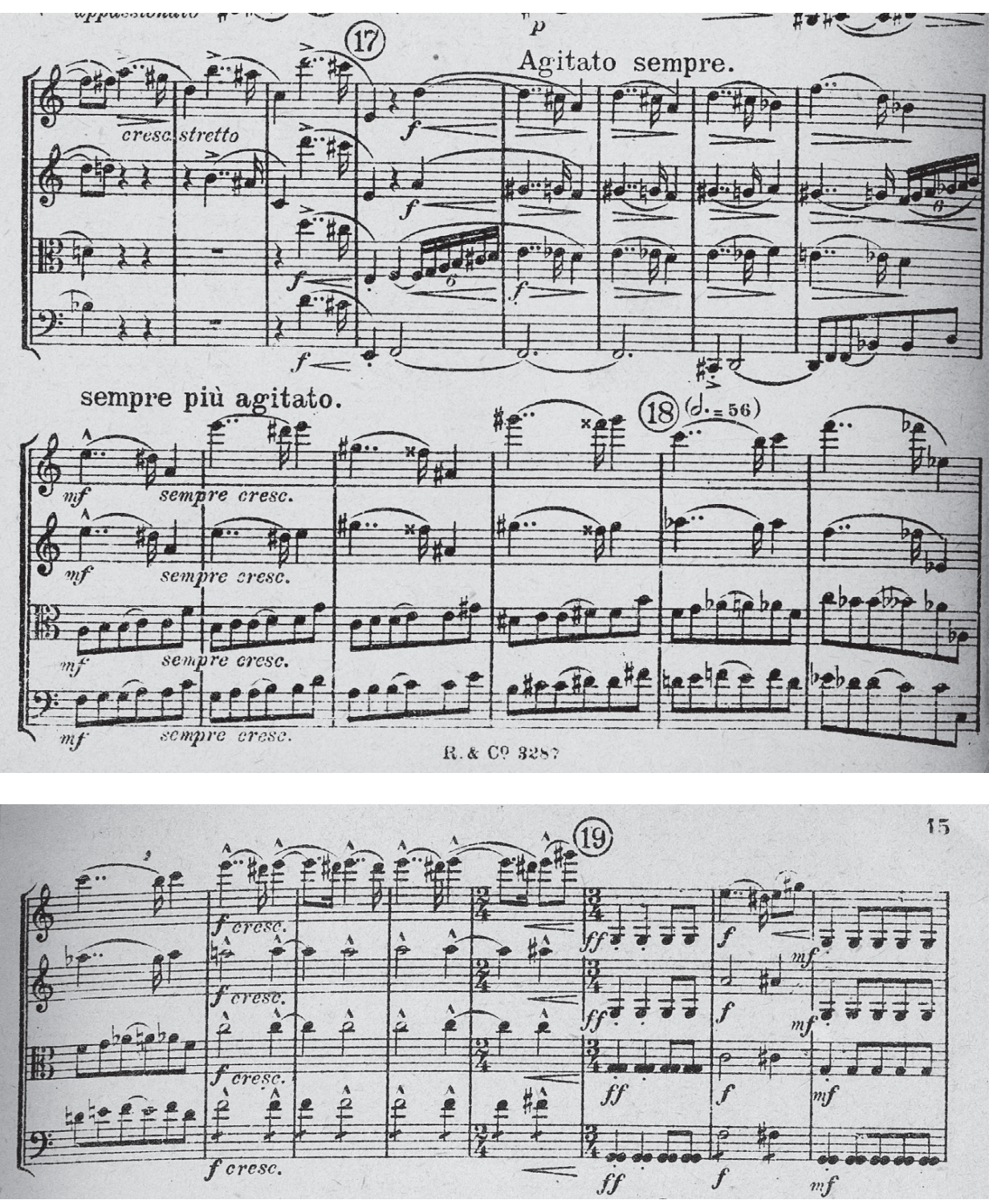
FACSIMILE 4 Discarded measures in the autograph score of the First String Quartet, first movement

Reproduced by kind permission of the Paul Sacher Stiftung, Basel

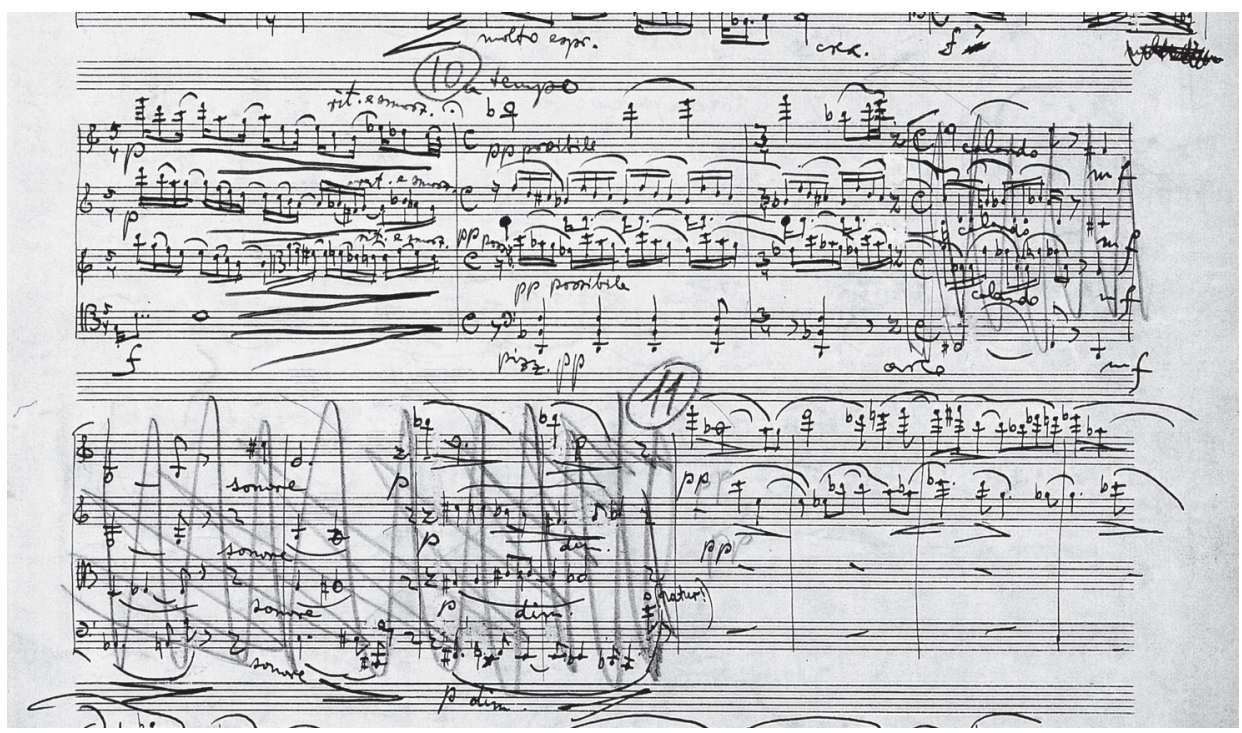

the opening theme now reflect a progressively building momentum. The original, which included the gradually decreasing tempo in the five deleted measures, was undoubtedly lengthy. Perhaps it would be extensive in the performance of a string quartet, yet this passage could have been effective in Bartók's presentation at the piano. It is not an exaggeration to suppose that during the composition of his first quartet, the young Bartók partly composed at the piano; he certainly tested his new scores at his instrument, including the string quartet. In his performance he may not have detected issues with the $\boldsymbol{m f}$ - - sonore - - $\boldsymbol{p}$ - - diminuendo measures. Later recordings of Bartók's piano performances demonstrate how suggestive he was in presenting sudden changes. ${ }^{9}$ Fortunately, his friend Kodály, who was himself incidentally a cellist, identified the risk of such details in this string quartet score. This led Bartók to improve these sections, either through rewriting or deletion.

I now return to the sonata-form second movement of the quartet. Corrections in the autograph score beyond the discarded B-A-C-H vision demonstrate that

9. E.g. in the coda of the opening movement of Beethoven's "Kreutzer" Sonata op. 47, as the piano replies to the phrase of the violin; the Joseph Szigeti - Bartók 1940 live performance of Beethoven's "Kreutzer" Sonata op. 47, see in Bartók at the Piano 1920-1945, ed. by László SOMFAI, Zoltán KOCSIS and János SEBESTYÉN (Budapest: Hungaroton, 1991, HCD 12326-31). 
FACSIMILE 5 The original mm. 101ff under the paste-up in the autograph score of the First String Quartet, second movement Reproduced by kind permission of the Paul Sacher Stiftung, Basel
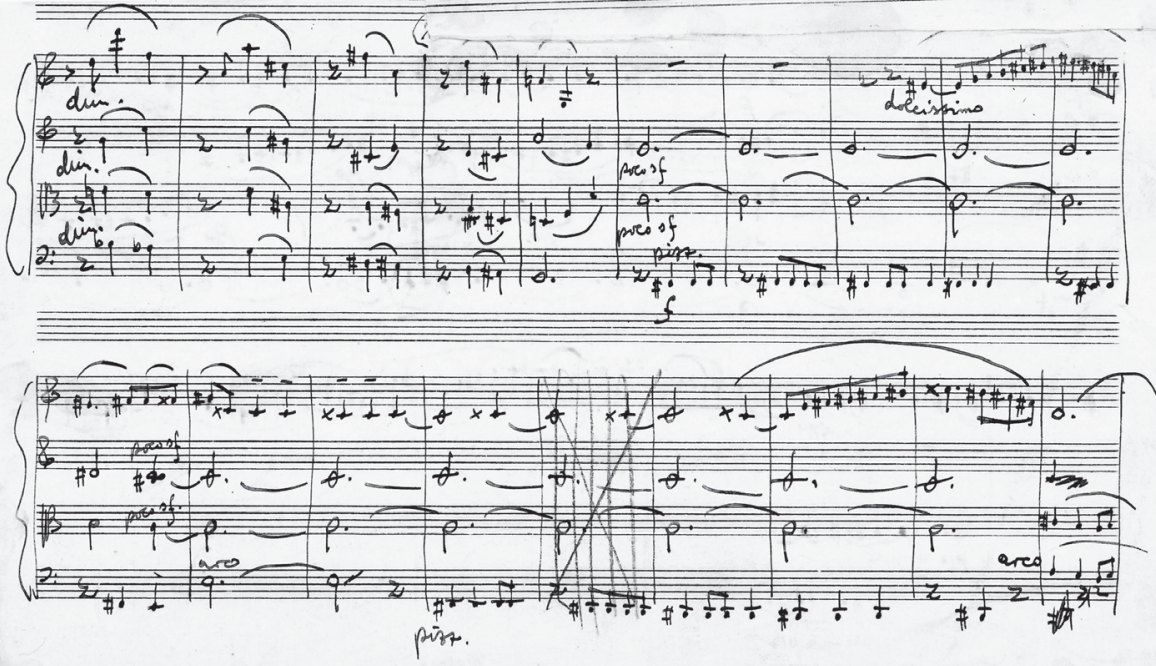

FACSIMILE 6 The corrected mm. 101ff under the paste-up in the autograph score of the First String Quartet, second movement Reproduced by kind permission of the Paul Sacher Stiftung, Basel

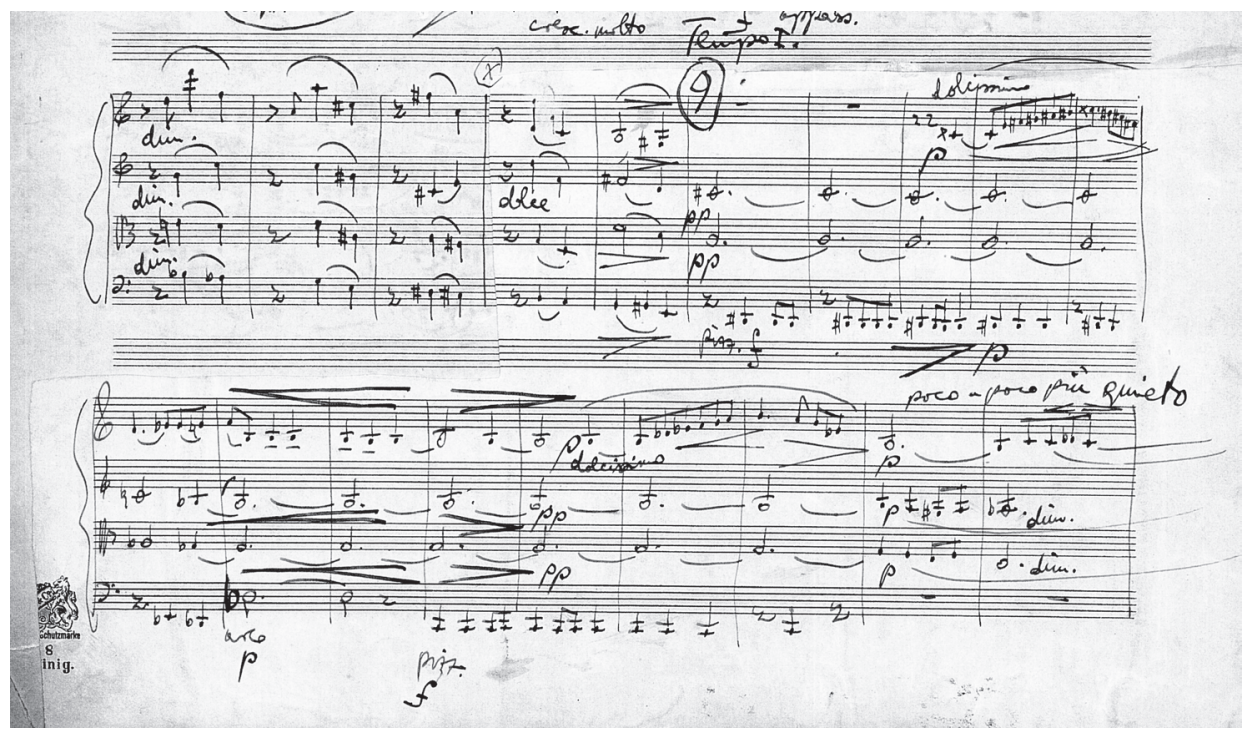


in contrast to his adherence to the key and octave of these initial thematic ideas (even in the full score at their first appearance) in the following stages of their elaboration Bartók made transpositions unhesitatingly when he deemed these adjustments more effective. One such transposition occurs in the exposition of the second movement: in the corrected version (Facsimile 6), upon the second appearance the cello with the pizzicato notes could much more effectively produce the "drumming" effect on the open $\mathrm{C}$ string then in the discarded first version on D-sharp (Facsimile 5).

Incidentally the first version reproduced here (Facsimile 5) was unknown to scholars until recently. It is important to note that rather than discarding entire pages or bifolios during the compositional process, it was Bartók's habit to cover discarded versions by paste-ups - sometimes even half- or three-quarter-page-sized paste-ups. Such inserts in the manuscripts which Bartók left in Budapest were opened and studied decades ago in the Budapest Bartók Archives under Denijs Dille's directorship. Nevertheless, the paste-ups were left intact in the greater part of the primary sources in the American Bartók Estate (now deposited in the Paul Sacher Stiftung), including the autograph score of the First String Quartet discussed in this article. During the preparation of the string quartet volumes in the Béla Bartók Complete Critical Edition, the paste-ups of the autograph score of the First String Quartet were opened in 2019 in the Paul Sacher Stiftung, thanks to László Vikárius's mediation and Director Felix Meyer's permission. Beyond the revision of 8 measures between rehearsal numbers 10 and 11, the transposition reproduced here is the only significant paste-up in this movement.

With or without the B-A-C-H motive? In its finalized form the Allegretto second movement of Bartók's First String Quartet is such original and multifaceted music that a confusing reference to the famous musical cryptogram would not only be superfluous, but trivial.

Open Access. This is an open-access article distributed under the terms of the Creative Commons Attribution 4.0 International License (https://creativecommons.org/licenses/ by/4.0), which permits unrestricted use, distribution, and reproduction in any medium, provided the original author and source are credited, a link to the CC License is provided, and changes - if any - are indicated. 